\title{
Demystifying Language about Students' Varied Identities
}

\author{
Jason T. Black \\ School of Business and \\ Industry \\ Florida A\&M Univ. \\ Jason.Black@famu.edu
}

\author{
Kamau Bobb \\ Constellations Center \\ for Equity \& \\ Computing \\ Georgia Tech \\ kamau.bobb@cc.gatech. \\ edu
}

\author{
April Browne \\ Computer Science Dept. \\ Butte College \\ Oroville, CA, USA \\ browneap@butte.edu
}

\author{
Phillip T. Conrad \\ Computer Science Dept. \\ UC Santa Barbara \\ Santa Barbara, CA \\ conrad@acm.org
}

\author{
Colleen M. Lewis \\ Computer Science Dept. \\ Harvey Mudd College \\ Claremont, CA, USA \\ lewis@cs.hmc.edu
}

\author{
Cherly A. Swanier \\ Math and CS Dept. \\ Claflin University \\ Orangeburg, SC, USA \\ cswanier@claflin.edu
}

\author{
Sheila Tejada \\ Computer Science Dept. \\ University of Southern California \\ Los Angeles, CA, USA \\ stejada@usc.edu
}

\begin{abstract}
The goal of the session is to help attendees who are committed to diversity and inclusion learn to talk about different dimensions of identity (e.g., race, class, gender, sex, sexuality, etc.). The landscape of terms is always changing and we want SIGCSE attendees to feel more comfortable using current language to talk about issues related to diversity and inclusion. This special session will include six lightning talks, individual reflection, small-group discussion, and a Q\&A with presenters. This is a reprise of a special session held at the NCWIT Summit in 2018; it was well received and we hope to offer it to the larger SIGCSE audience.
\end{abstract}

\section{SUMMARY AND GOALS}

We seek to provide resources and definitions for discussing students' identities. After each lightning talk, attendees will have the opportunity to practice applying these ideas through individual reflection and small-group discussion. On the NCWIT Summit survey, the session was described as amazing, actionable, inspiring, interactive, and valuable. $88.7 \%$ of survey respondents $(\mathrm{N}=141)$ agreed or strongly agreed that they feel more comfortable discussing complex topics such as race, ethnicity, and sexual orientation in their classroom after the session.

\section{STRUCTURE AND TOPICS}

We will begin by repeating the following structure three times:

- $\quad$ Two lightning talks ( 7 min with transitions)

- Individual reflection on discussion prompts ( 3 min)

- Discussion in small groups ( $\sim 7 \mathrm{~min})$.

The remaining time will be used for Q\&A with the presenters.

Permission to make digital or hard copies of part or all of this work for personal or classroom use is granted without fee provided that copies are not made or distributed for profit or commercial advantage and that copies bear this notice and the full citation on the first page. Copyrights for third-party components of this work must be honored. For all other uses, contact the owner/author(s). SIGCSE '19, February 27-March 2, 2019, Minneapolis, MN, USA

(C) 2019 Copyright is held by the owner/author(s).

ACM ISBN 978-1-4503-5890-3/19/02.

https://doi.org/10.1145/3287324.3287513
The session will be facilitated by Dr. Cheryl Swanier. Dr. Swanier is the Department Chair of Mathematics and CS and an Associate Professor of CS at Claflin University where she is named the Henry N. and Alice Carson Tisdale Endowed Professor.

\subsection{Family Friendly-April Browne}

Students with caregiving responsibilities are a hidden diversity with their own set of challenges. There are many ways that institutions, as well as faculty, can be more family friendly. Attendees will discuss:

- What additional problems or supports for student caregivers have you seen or heard about?

- What course policies do you have that could have a differentially negative impact on student caregivers?

- What kinds of supports does your school or community have for student parents? How might they be improved?

April Browne is a Computer Science instructor at Butte College in northern California. She has been teaching introductory level programming classes at Butte for the past three years She has had the opportunity to interact with student parents while her children have participated in the on-campus childcare. This has led to her interest in advocating for student caregivers.

\subsection{Ability and Ableism-Colleen Lewis}

We might think about classroom accommodations as valid when they apply to physical health, but not mental health. While no accommodation is going to be perfect, mental health is physical and it is probably wise to trust experts to help make our classroom accessible. There are ways we can change our language and behavior to avoid ableism, i.e., bias or discrimination in favor of able bodied people. Attendees will discuss:

- How do you (or could you) make accommodations just part of your regular teaching practice?

- Can you think of tasks in tech careers that are similar to tests? Are these tasks required in all roles? 
- How might you respond to your colleagues who are resistant to providing accommodations?

Colleen Lewis is the McGregor-Girand Associate Professor of CS. Her research seeks to identify effective teaching practices for creating equitable learning spaces for all students. Lewis curates CSTeachingTips.org, a NSF-sponsored project for disseminating effective CS teaching practices.

\subsection{Gender and Sexuality-Phill Conrad}

Are gender, sex and sexuality issues in the CS classroom? We address this with real-world stories. We discuss the benefits of sharing one's pronouns (she/her/hers vs. he/him/his vs. they/them/their) and inviting students to share theirs. We identify four aspects of personal identify: sex, gender identity, gender expression and sexual orientation, and invite attendees to discuss:

- $\quad$ "Someone left their umbrella; I hope they get it." Is this sentence grammatically correct? What is your level of comfort with the singular they?

- We may ask students: "What are your preferred gender pronouns" or may simply ask "what are your pronouns". Discuss: pros/cons, why it might matter.

- Which aspects of personal identity (sex, gender identity, gender expression and sexual orientation) are you the most (or least) comfortable discussing, and why?

- Cameron uses the pronouns "they/them/their." Try using Cameron's name and their pronouns in a sentence.

Phill Conrad is a Senior Lecturer at the University of California, Santa Barbara; he has been on the UCSB CS faculty since 2008. Before that, he was CS faculty at Temple University, and the University of Delaware, where he earned his Ph.D. in CS.

\subsection{Privilege, Racism, and Implicit Bias-from the Eyes of Black Men-Jason Black}

This presentation discusses the racism and bias that black men face daily, both in society and more specifically in academia, and how these biases create stereotypes that prove a deterrent to their educational and personal progress. Also presented is a frank discussion of racism and privilege and how many of us can hold racist or prejudicial views toward black men as a consequence of being a member of a "privileged" group. An additional focus is on strategies for counteracting bias. Attendees will discuss:

- Would you consider yourself part of a privileged group? How has that shaped your view of Black Men?

- Do you hold any of the stereotypes or biases presented? If so, how do you plan to address this? If not, how do you think you have been able to avoid these?

- What is the most significant take-away from today that will shape your future interactions with Black Men?

- Do you belong to a group that has been traditionally hostile in its views toward Black Men? If so, how do you plan to address that group on this issue?
Dr. Black, Associate Professor in Business Information Systems, holds a MS degree in CS from Georgia Tech, and a $\mathrm{PhD}$ in CS from Florida State University. Dr. Black has a research background in mobile computing, collaborative learning and educational technology. Dr. Black founded and directed the NSFfunded African-American Women in CS Scholarship program, and was a founding partner in the NSF-funded STARS Alliance for Diversity in Computing. Dr. Black also is working in Big Data, Social Computing, Social Media, and Entrepreneurship.

\subsection{Race Labels-Kamau Bobb}

This presentation explains the introduction and evolution of racial categorization and race as a social construct. Racial categorization obscures multiple dimensions of heterogeneity within racial groups. The talk will explain why the terms "minority" and "non-White" have been critiqued and how they can be replaced by "minoritized" and "person of color." Attendees will discuss:

- In your role at your institution, when/why does it matter to refer to anyone or any group by racial identity?

- Have you ever wanted to know someone's race? If so, why? Was it necessary for you to know?

- Have you noticed a tendency to avoid race labels and instead refer to individuals or groups as "diverse" or "ethnic" or "minority"? Why might this be problematic?

Dr. Bobb's work focuses on the relationship between equity for students and communities of color in the STEM enterprise, society, and large educational systems. Dr. Bobb holds a PhD in Science and Technology Policy from Georgia Tech and M.S. and B.S. degrees in Mechanical Engineering from UC Berkeley.

\subsection{Model Minority-Sheila Tejada}

While the term "Model Minority" might seem like a complement, it is a myth that can place additional pressure on people of Asian descent and serve to silence students from asking for help they may need. It can reinforce racial hierarchies that denigrate other marginalized groups, and hide the variations in experiences among people of Asian descent. Attendees will discuss:

- Stereotypes can treat a group of people as homogeneous. In what ways can this be harmful?

- As educators, how we can become more aware of bias?

- What resources can we give our students to educate them about stereotypes and bias?

- About $20 \%$ of CS undergrads are Asian. At your school, what challenges and stereotypes may they face?

Dr. Tejada is currently a professor in the CS Department at the University of Southern California, in Los Angeles (LA), where she teaches courses and performs research applying artificial intelligence, machine learning and robotics in education. As the academic community leader for Anita Borg Institute.LA, she is passionate about empowering a diverse tech community in LA. 